\title{
Thin-Film Photovoltaics
}

\author{
Gaetano Di Marco ${ }^{1}$ and Leonardo Palmisano ${ }^{2}$ \\ ${ }^{1}$ CNR-Istituto per i Processi Chimico-Fisici, Viale Ferdinando Stagno d'Alcontres, 3798158 Messina, Italy \\ ${ }^{2}$ Dipartimento di Ingegneria Elettrica, Elettronica e delle Telecomunicazioni, Università di Palermo, Viale delle Scienze, \\ 90128 Palermo, Italy
}

Correspondence should be addressed to Leonardo Palmisano, palmisano@dicpm.unipa.it

Received 2 November 2010; Accepted 2 November 2010

Copyright (C) 2010 G. Di Marco and L. Palmisano. This is an open access article distributed under the Creative Commons Attribution License, which permits unrestricted use, distribution, and reproduction in any medium, provided the original work is properly cited.

A solution to obtain energy in a sustainable manner for the environment and to benefit the people of the earth is the use of the sun as a primary source. The development of new technologies is strategic for the scientific community and is a challenge for the 21st century. In fact, the amount of energy that the sun radiates into the earth is about ten thousand times greater than what mankind uses.

Thin-film photovoltaic systems are quickly diffusing in these last years, and they now account for some $12 \%$ of solar installation around the world. Thin-film (TF) photovoltaic cells are less expensive to manufacture than the traditional crystalline silicon-based ones and have considerably lowered the barrier to the entry into the photovoltaic energy business. Significantly, the production cost of first solar CdSe modules is now lower than $1 \$ / W_{p}$. The sector is thus rapidly switching from the heavy fragile silicon panels to thin-film technologies which use a number of different inorganic and organic photovoltaic (PV) semiconductors, and the revenue market share of TFPVs is expected to rise very much next years.

This special issue collects some research papers mainly reporting preparation, characterization, and testing of thinfilms, some of which could be of importance in the near future by an application point of view to assemble new photovoltaic cells.

The essentials of each papers are described below.

Progress in Polycrystalline Thin Film CGIS Solar Cells. A variety of methods are presented to prepare CIGS $\left[\mathrm{Cu}(\mathrm{InGa}) \mathrm{Se}_{2}\right.$ or $\left.\mathrm{Cu}(\mathrm{InGa})(\mathrm{Se}, \mathrm{S})_{2}\right]$ thin films, and important parameters (optoelectronic properties, substrates, partner layers) are assessed to improve efficiency of solar cells.

Preparation and Characterization of $\mathrm{Sb}_{2} \mathrm{Te}_{3}$ Thin Films by Coevaporation. New materials such as $\mathrm{Sb}_{2} \mathrm{Te}_{3}$ have the peculiarity of forming a stable ohmic back contacts with CdTe; as a matter of fact, the cadmium telluride shows interesting performances for photovoltaic applications. Electrical properties, structure, morphology, and preparation of antimony telluride are described.

Investigation of Low-Cost Surface Processing Techniques for Large-Size Multicrystalline Silicon Solar Cells. A simple method is presented to enhance conversion performance in large-size solar cells using multicrystalline silicon (mc-Si) wafer. In particular, a single layer (SL) and dual layer (DL) of silicon nitride $\left(\mathrm{Si}_{3} \mathrm{~N}_{4}\right)$ are deposited in mc-Si by plasmaenhanced chemical vapor deposition. Quantum efficiency measurements show that DL coating can get the best results.

Efficiency Improved by $\mathrm{H}_{2}$ Forming Gas Treatment for SiBased Solar Cell Application. Forming gas treatments (FG) on single-crystalline (sc) and on multicrystalline (mc) silicon ( $\mathrm{Si}$ ) components useful for solar cells improve their photovoltaic effects. The increment is larger in mc-Si than in sc-Si. The internal quantum efficiency increases with FG, especially in the visible region.

Lateral Infrared Photovoltaic Effects in Ag-Doped ZnO Thin Films. Ag-doped $\mathrm{ZnO}$ thin films exhibit a lateral-induced 
photovoltage under $1064 \mathrm{~nm}$ pulse laser radiation. High photovoltaic responsivity and position sensitivity values are observed. This circumstance proposes the $\mathrm{ZnO}$ thin film as a good candidate for IR position photo-detector.

Organic Solar Cells: Problems and Prespectives. The use of semiconducting conjugated polymers in organic-based photovoltaic (OPV) cells is discussed as a current research topic. In this brief review, some interesting aspects connected to efficiency, diffusion, dissociation, and transport charge of the aforesaid material are described.

ZnO-Nanorod Dye Sensitized Solar Cells: New Structure without a Transparent Conducting Oxide Layer. Dye-sensitized solar cells (DSSCs) based on $\mathrm{ZnO}$ nanorod/film structure without transparent conducting oxide (TCO, typically fluoride-doped tin oxide/FTO) and two preparation methods are proposed. The new DSSCs yield interesting photovoltaic features.

Bridged Phthalocyanine Systems for Sensitization of Nanocrystalline $\mathrm{TiO}_{2}$ Films. The paper explains the construction of DSSCs by using metal phtalocyanines and their derivatives. The reason why these dyes are considered "appealing materials" is pointed out. Furthermore, the synthesis strategy for conjugated superchromophore is presented.

Preparation of a counter Electrode with p-Type NiO and its Applications in Dye Sensitized Solar Cell. The effect of counter electrode with a p-type semiconductor ( $\mathrm{NiO}$ film) on power conversion efficiency of DSSC, is investigated. The study compares different cathodes, and a photoelectrochemical analysis is carried out. It seems that the $\mathrm{NiO}$ film increases the electrocatalytic activity of the counterelectrode.

Metal Nanoparticles and Carbon-Based Nanostructures as Advanced Materials for Cathode Application in Dye-Sensitized Solar Cells. Advanced methods for the fabrication of cathodes for DSSCs, employing nanostructured materials, are reviewed. The attention is focused on metal nanoparticles and nanostructured carbon, among which nanotubes and graphene, whose good catalytic properties make them ideal for the development of high performance catalyst materials.

Fabrication of Dye Sensitized Solar Cells with a 3D Nanostructured Elettrode. An original photoanode for DSSCs is fabricated. The electrode is realized by a sputtered $3 \mathrm{D}$ nanostructured indium tin oxide (ITO), electrophoretic deposition of $\mathrm{TiO}_{2}$ nanoparticles and dye sensitization. The final device reveals improved performances in respect to the conventional ones.

New Components for Dye-Sensitized Solar Cells. DSSCs are third-generation photovoltaic devices that can be used in various applications, due to their low cost and ease of fabrication. In this contribution, recent advances in molecular sensitizers, electron mediators, conductive polymers, and catalytic materials are reviewed.

Characterizations of Chitosan-Based Polymer Electrode Photovoltaic Cells. Solid polymer electrolytes are employed in the fabrication of solid-state photoelectrochemical cells. Several electrolytic compositions, electrical conduction, and photoelectrical performance are reported. Dyes extracts from local vegetables are also used to reduce the environmental impact.

Debundling and Selective Enrichment of SWNTs for Applications in Dye-Sensitized Solar Cells. The state of the art is reviewed on the use of single-wall carbon nanotubes (SWNTs) in DSSCs, where they can serve multiple purposes. The paper, together with a wide and comprehensive critical analysis of the literature, highlights the possible strategies and indicates a few useful directions for future research to improve the performance of nanotube-based DSSCs.

Gaetano Di Marco Leonardo Palmisano 


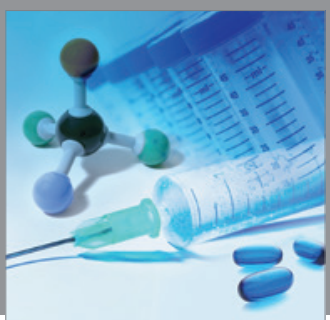

International Journal of

Medicinal Chemistry

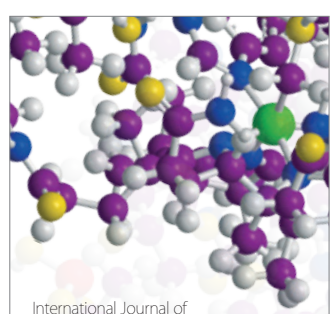

Carbohydrate Chemistry

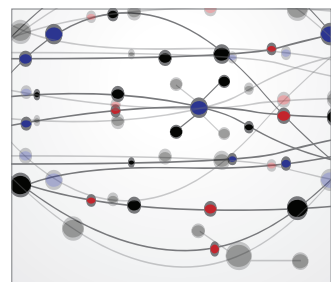

The Scientific World Journal
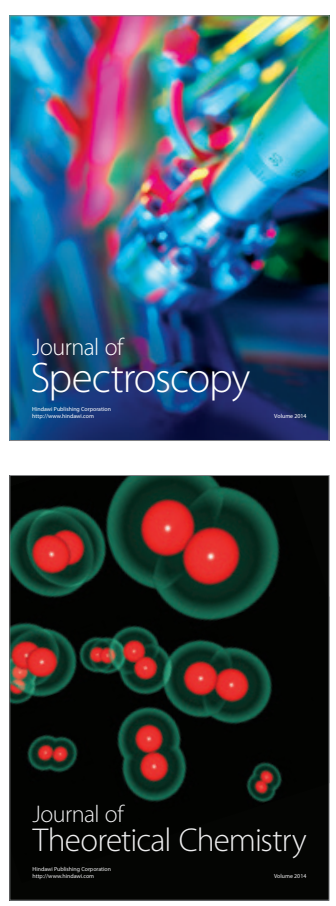
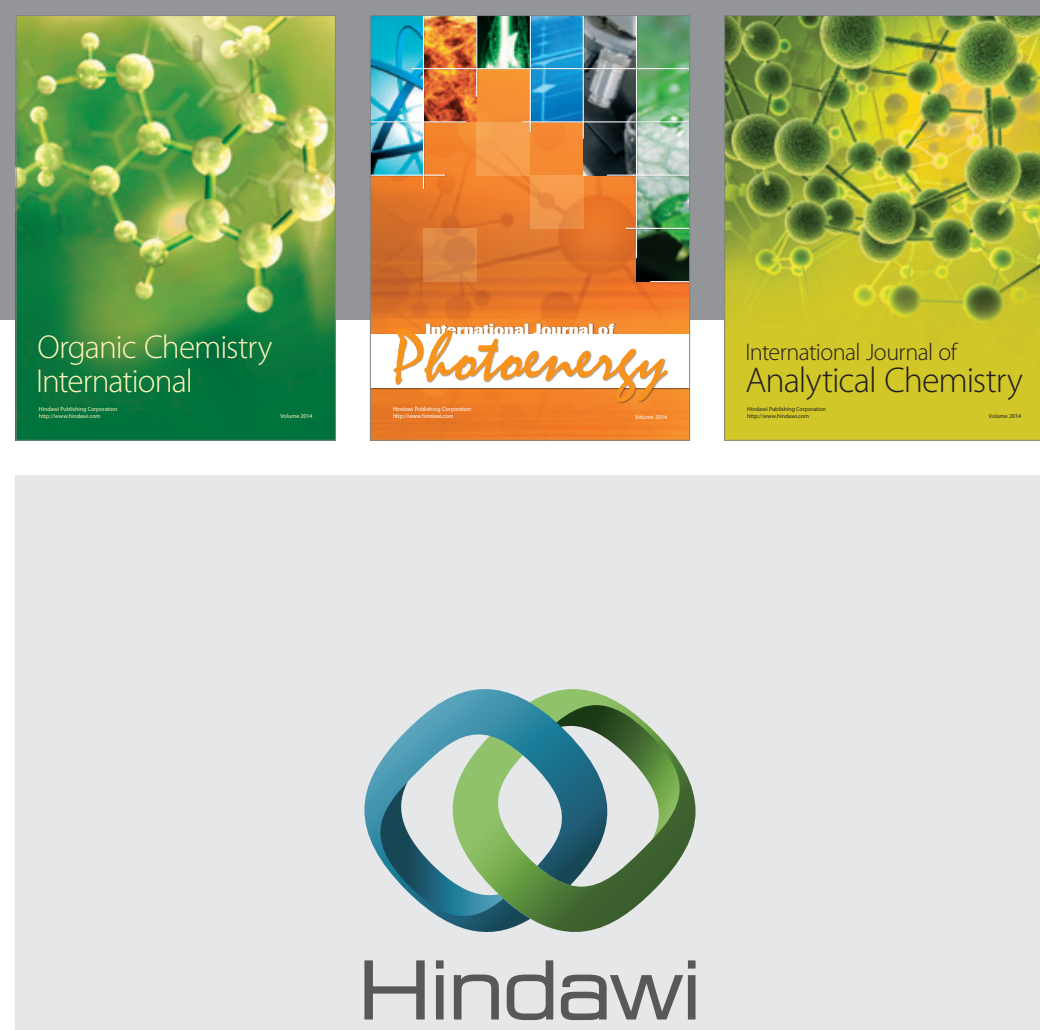

Submit your manuscripts at

http://www.hindawi.com
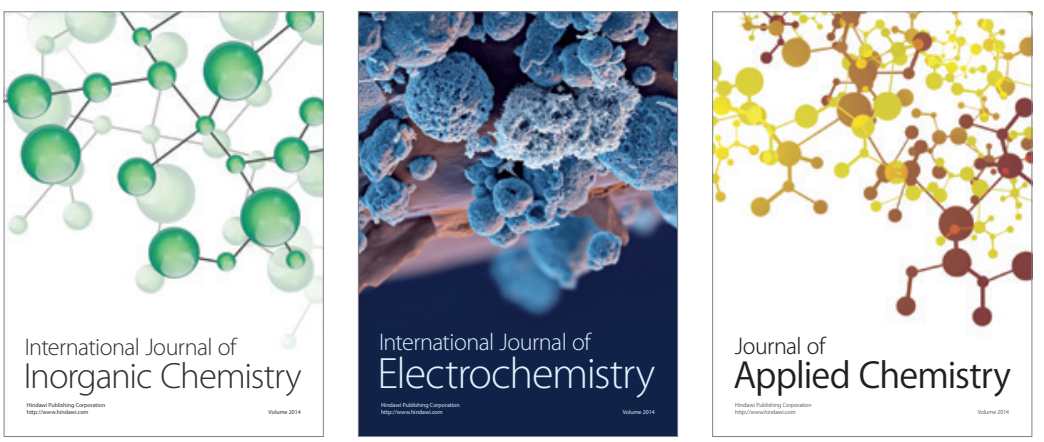

Journal of

Applied Chemistry
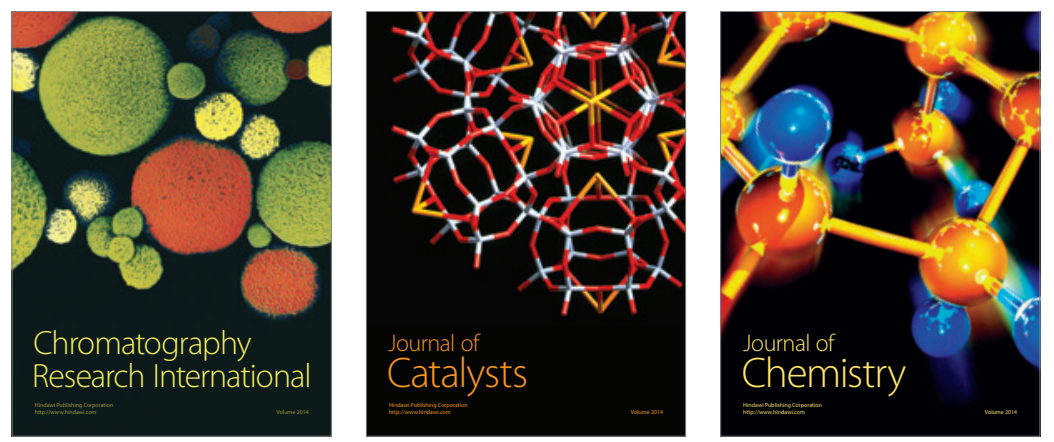
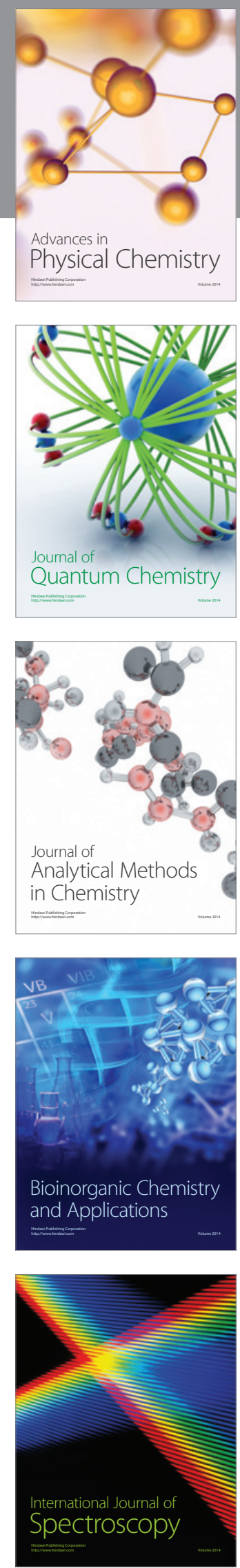